\title{
REFLECTIONS \\ Ten years of ART in South Africa - how far we have come
}

\author{
C Serenata, BA (Hons), MBA \\ Corresponding author: C Serenata (cserenata@clintonhealthaccess.org)
}

Celicia Serenata is Director, HIV and TB, Strategic Advisor for the Clinton Health Access Initiative based in Boston, USA

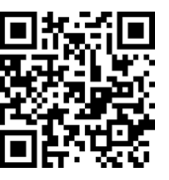

I became involved in the HIV response in 1999, when I joined the HIV, AIDS, STI and TB (HAST) unit within the National Department of Health. Little did I know in 1999 that HIV would become my life. I had already been working in public health since 1993, and had been on the fringes of HIV, through the interdepartmental HIV and AIDS committee. At that point, the focus was on HIV awareness for public sector workers, and success was measured by the availability of condoms.

\section{'This was my first exposure to the small world of HIV in South Africa - filled with many interest and stakeholder groups, all with honourable intentions, but not always on the same page.'}

The first task we had after I joined the HAST unit was to participate in the writing of the new national strategic plan (NSP) covering the period 2000 - 2005. This was my first exposure to the small world of HIV in South Africa - filled with many interest and stakeholder groups, all with honourable intentions, but not always on the same page. Fifteen years later, I am happy to say that I think this has definitely changed, for the better.

This is where I was introduced to the process of stakeholder consultation, and through trial and error, we ended up with a document upon which we could all agree. When we wrote that plan, the antenatal seroprevalence rate among pregnant HIVpositive women was $22.4 \%$, with around 4.2 million people living with HIV; and of course, this would climb over the next few years to around $30 \%$, and around 5.6 million people living with HIV. At this point there were no public sector treatment programmes, though there were some patients receiving antiretroviral therapy (ART) in research programmes. However, the NSP 2000 - 2005 put into words the intention to change this, and had as one of its four strategies: 'Improve the care and treatment of HIV-positive persons and persons living with AIDS to promote a better quality of life and limit the need for hospital care'.
Honestly, we did not really know what this would involve, but the NSP opened the door to allow us to start thinking about it. Unfortunately, it would take another three years for that thinking to be put into action. Following a meeting between then President Thabo Mbeki and former US President Bill Clinton, the then Minister of Health, Manto TshabalalaMsimang, put together a task team to develop an operational plan for implementing comprehensive care, management and treatment of HIV in the public sector. Bringing together technical expertise from the Clinton Foundation, local clinical practitioners, academics and government officials, we started working for many months to put together what was then a revolutionary plan to introduce ART. I will not dwell on the politics of HIV at the time, but suffice it to say that there were equal amounts of enthusiasm and resistance being experienced at the time of writing the plan.

My life became consumed by writing this plan. The task team pretty much lived out of the sixth floor of a Pretoria hotel. We would work from morning to midnight, catch a few hours of sleep, and then start all over again. Writing, consulting, rewriting, reviewing, submitting for review, incorporating comments, visiting provinces and facilities. And repeat. And repeat. And again.

Draft after draft was critiqued and rejected, but still we kept on going. We did so because we knew that the pay-off was something to which we were all so committed. That period of working with 20 or so hardworking, visionary individuals was the most rewarding professional experience. Ten years after joining the public health sector, I was participating in something that would be revolutionary.

\section{'I will not dwell on the politics of HIV at the time, but suffice it to say that there were equal amounts of enthusiasm and resistance ...'}

Through the blood, sweat and tears (it was a 258-page document!), we would come out victorious. On my birthday, 19 
November 2003, I received a call from my boss, Dr Nono Simelela, with the best five words I could have wished for: 'Cabinet just approved the plan!' This was before 10 am in the morning. I went to the nearest bar, and had a large cocktail to celebrate.

\section{'... with vision, collective response and commitment, we can overcome obstacles for the improvement of the health of all who live within the borders of South Africa ...'}

Once the plan was approved, we seemed to move at warp speed. Putting in place the budget, people and systems to introduce ART in the public sector required a monumental effort from government, clinicians, advocacy groups and civil society in general. Participating in facility visits to ensure that everything was in place to initiate patients, the massive training effort that had to be rolled out, job aides, guidelines - it was intoxicating. When Thursday 1 April 2004 rolled around, it felt like the culmination of something that started in mid-1999 when we started working on the NSP.
I was also there when another Minister of Health, Aaron Motsoaledi, inspired us to think bigger, collectively, by pushing for the decentralisation of treatment from mainly hospitals to primary healthcare services. By April 2010, treatment was offered in fewer than 500 facilities - by the end of 2013 that number had risen to over 3500 , and the number of people receiving ART, from under 1 million to over 2 million.

I look forward to the next challenge - with more than 5.6 million people living with HIV, there are many more millions that need to be initiated on ART in the next decade - and this within the existing public sector constraints. However, knowing where we were ten years ago, I have faith in our ability, collectively, to make this happen successfully. As a society we have shown that with vision, collective response and commitment, we can overcome obstacles for the improvement of the health of all who live within the borders of South Africa, and I hope to be a part of this for the next decade, and beyond.

Conflict of interest. This work is written in Ms Serenata's personal capacity and does not necessarily represent the views of the Clinton Health Access Initiative.

S Afr J HIV Med 2014;15(1):14-15. DOI:10.7196/SAJHIVMED.1028 